\title{
14 The nexus between water, energy, and food (WEF) systems in Northern Canada
}

\author{
David Natcher \& Shawn Ingram
}

\section{Introduction}

In 2015, the United Nations introduced Transforming the World: the 2030 Agenda for Sustainable Development. The 2030 Agenda was endorsed by the world's leaders to serve as an action-oriented road map for safeguarding the welfare of current and future generations (Lim, Søgaard Jørgensen, \& Wyborn, 2018). At the core of the Agenda are 17 Sustainable Development Goals (SDGs) that serve as benchmarks for achieving equality, prosperity, and environmental sustainability. Each of these 17 SDGs has specific targets $(N=169)$ and associated indicators $(N=232)$ that are used to measure advancements toward the attainment of each SDG.

While Agenda 2030 has been heralded as a platform for protecting our environment for current and future generations, some (e.g., Nilsson, Griggs, $\&$ Visbeck, 2016) warn that simply "ticking off” SDG targets without considering cross-sectoral interactions may result in ill-informed and unintended outcomes. For example, Lim et al. (2018) argue that there is an inherent risk in global goal formation, whether in the case of SDGs or its predecessor, the Millennium Development Goals, when targets are compartmentalised, siloed, and viewed through a reductionist lens (Costanza et al., 2015; Nilsson $\&$ Costanza, 2015). In these cases, the complexities of individual SDGs may be obscured, and critical interactions in the global system can go unnoticed (Lim, Søgaard Jørgensen, \& Wyborn, 2018). The United Nations acknowledges the risks of treating SDGs as discreet and unrelated and has called for greater attention to the interactions between SDG targets. This includes careful consideration of both the synergies and trade-offs associated with SDG attainment. Synergies include the positive effects of achieving multiple SDG targets through simultaneous interventions, for instance through mutually beneficial infrastructure developments, whereas trade-offs occur when advancements toward one target have a negative impact on the ability to reach other targets, whether due to environmental degradation or intensive use of resources (Fader, Cranmer, Lawford, \& Engel-Cox, 2018). For example, Pradhan, Costa, Rybski, Lucht, and Kropp (2017) found that SDG 1 (Ending poverty) has synergetic relationships with most of the 
other SDGs, while SDG 12 (Responsible consumption and production) is most commonly associated with trade-offs. Accounting for the positive and negative spillover effects of SDG attainment is therefore essential to formulating sustainable solutions to global challenges (McCollum et al., 2018; Rasul, 2016).

Various methodologies have been developed to systematically map and rank the level of interactions between SDG targets (Nilsson, Griggs, \& Visbeck, 2016). These approaches have generally been referred to as nexus research and are used to define, measure, and analyse the connections and interactions between SDGs. There are multiple fields of nexus research but the relationship between water (SDG 6), energy (SDG 7) and food (SDG 2) (WEF) has received considerable research attention (Endo, Tsurita, Burnett, \& Orencio, 2017). This focus has been attributed, in large part, to the pervasive interactions that occur between WEF systems (Bhaduri, Ringler, Dombrowski, Mohtar, \& Scheumann, 2015; Biggs et al., 2015).

Over the past decade, WEF nexus studies have been conducted at the global (Fader, Cranmer, Lawford, \& Engel-Cox, 2018), national (Mainali, Luukkanen, Silveira, \& Kaivo-Oja, 2018), and regional levels (Kulat, Mohtar, \& Olivera, 2019; Liu, 2016), and all have concluded that WEF nexus research is informative for resource planning and developing effective policies for sustainable development (Pittock, Orr, Stevens, Aheeyar, $\&$ Smith, 2015). This was the impetus for the Arctic Council to adopt the United Nations' SDGs to inform its own strategic policy direction; noting the 2030 Agenda for Sustainable Development is global in scope but also applicable to Arctic regions. In particular, the Arctic Council's Sustainable Development Working Group (SDWG) endorsed the principles of Agenda 2030 and made a commitment to use SDG targets as guideposts for advancing the sustainable development of Arctic regions (SDWG, 2017). Yet before those guideposts can be determined, the SDWG acknowledged that a better understanding of the potential synergies and trade-offs between SDG targets was needed before regional implementation could be considered.

Although WEF nexus studies have been conducted in regions around the world, no assessment has been conducted in an Arctic setting. It is in this context that our study for northern Canada was conducted. As defined by the Arctic Council, northern Canada includes Yukon, Northwest Territories, Nunavut, Nunavik, and Labrador. This study serves as a preliminary assessment of the nexus between: SDG 2-ending hunger and achieving food security for all; SDG 6-ensuring the availability and sustainable management of water and sanitation for all; and SDG 7-ensuring access to affordable, reliable, sustainable, and modern energy for all (Table 14.1). By evaluating the current state of WEF security in northern Canada, and making visible the synergies and trade-offs between WEFSDG targets, policy makers in Canada will be in a more informed position 
Table 14.1 United Nations sustainable development goals and targets (SDG 2, 6, and 7)

\begin{tabular}{|c|c|}
\hline Goal 2 & $\begin{array}{l}\text { End hunger, achieve food security and improved nutrition and promote sustainable } \\
\text { agriculture. }\end{array}$ \\
\hline Target 2.1 & End hunger and ensure access to safe, nutritious and sufficient food all year round. \\
\hline Target 2.2 & End all forms of malnutrition. \\
\hline Target 2.3 & Double the agricultural productivity and incomes of small-scale food producers \\
\hline Target 2.4 & $\begin{array}{l}\text { Ensure sustainable food production systems and implement resilient agricultural } \\
\text { practices }\end{array}$ \\
\hline Target 2.5 & $\begin{array}{l}\text { Maintain the genetic diversity of seeds, cultivated plants and farmed and domesticated } \\
\text { animals and their related wild species. }\end{array}$ \\
\hline Target $2 \mathrm{a}$ & $\begin{array}{l}\text { Increase investment, including through enhanced international cooperation, in rural } \\
\text { infrastructure, agricultural research. }\end{array}$ \\
\hline Target $2 \mathrm{~b}$ & Correct and prevent trade restrictions and distortions in world agricultural markets. \\
\hline Target $2 c$ & Adopt measures to ensure the proper functioning of food commodity markets. \\
\hline Goal 6 & Ensure availability and sustainable management of water and sanitation for all. \\
\hline Target 6.1 & Achieve universal and equitable access to safe and affordable drinking water for all. \\
\hline Target 6.2 & Achieve access to adequate and equitable sanitation and hygiene for all. \\
\hline Target 6.3 & Improve water quality by reducing pollution. \\
\hline Target 6.4 & $\begin{array}{l}\text { Substantially increase water-use efficiency across all sectors and ensure sustainable } \\
\text { withdrawals and supply of freshwater. }\end{array}$ \\
\hline Target 6.5 & $\begin{array}{l}\text { Implement integrated water resources management at all levels, including through } \\
\text { transboundary cooperation as appropriate. }\end{array}$ \\
\hline Target 6.6 & Protect and restore water-related ecosystems. \\
\hline Target 6a & $\begin{array}{l}\text { Expand international cooperation and capacity-building support to developing } \\
\text { countries in water-and sanitation-related activities and programmes. }\end{array}$ \\
\hline Target 6b & $\begin{array}{l}\text { Support and strengthen the participation of local communities in improving water and } \\
\text { sanitation management. }\end{array}$ \\
\hline Goal 7 & Ensure access to affordable, reliable, sustainable and modern energy for all. \\
\hline Target 7.1 & Ensure universal access to affordable, reliable and modern energy services. \\
\hline Target 7.2 & Increase substantially the share of renewable energy in the global energy mix. \\
\hline Target 7.3 & Double the global rate of improvement in energy efficiency. \\
\hline Target $7 \mathrm{a}$ & $\begin{array}{l}\text { Enhance international cooperation to facilitate access to clean energy research and } \\
\text { technology. }\end{array}$ \\
\hline Target $7 \mathrm{~b}$ & $\begin{array}{l}\text { Expand infrastructure and upgrade technology for supplying modern and sustainable } \\
\text { energy services for all }\end{array}$ \\
\hline
\end{tabular}

to carry out integrative planning. This is particularly necessary given the relatively high rates of WEF insecurities currently experienced in northern Canada compared to the rest of Canada (see CCA, 2014; Egeland, 2009; Natcher, Shirley, Rodon, \& Southcott, 2016; Poppel, 2015); insecurities that may be compounded by the social and ecological stresses that are expected to accompany climate change.

Following this introduction, we provide a brief review of the current status of WEF security in northern Canada. This includes current assessments of household food security, access to clean water, and dependence of non-renewable energy sources. We then discuss the data used in this assessment and the methodology employed to calculate interactions between WEF-SDG targets. Our results are then presented, and are followed by our conclusion that highlights our key findings and recommendations for future research. 


\section{WEF (in)security in Northern Canada}

Communities in northern Canada experience higher rates of water, energy, and food insecurity relative to the national average. These conditions have evoked national (e.g., CCA, 2014) and international attention (e.g., De Schutter, 2012). Below, we offer a general portrait of WEF systems in northern Canada.

\section{Water (in) security}

Nearly all residents in northern Canada have access to adequate drinking water and sanitation services. For example, roughly $99 \%$ of Inuit in Nunavut have hot and cold running water, a flush toilet, and a septic tank or sewage system (Poppel, 2015). However, northern Canada residents do not have universal access to improved water and sanitation services, with most gaps occurring in remote and rural areas (Bressler \& Hennessy, 2018). Approximately $74 \%$ of communities in Northwest Territories and Nunavut have trucked water supplies and waste disposal systems, with $16 \%$ having below/above ground water distribution systems, and $10 \%$ using a combination of water buckets, privies, or trucked services (Environment and Climate Change Canada, 2013). The overreliance on trucked water and waste removal has placed increased pressures on water utilities and constrains the ability for northern communities to deliver reliable water and sanitation services.

The quality of drinking water is also variable and is subject to seasonal fluctuations, often due to environmental or climate-related impacts, which at times affects water safety. In Nunavut, $13 \%$ of residents have indicated their water is not safe for drinking in general, while $21 \%$ indicated it is not safe for drinking at least some times throughout the year (Poppel, 2015). Nunavut residents have also indicated that environmental and climaterelated events have led to decreases in water quality and quantity, damage to water and sanitation infrastructure, and water maintenance and treatment issues (Bressler and Hennessy, 2018). The government of Northwest Territories (GNWT) reported that seven communities within the NWT had boil water advisories at some point in 2018 (GNWT, 2019). However, the GNWT anticipates climate change to have a negative impact on water quality and quantity, with detrimental changes caused by increased temperatures, extreme weather events, variability in precipitation, and impacts to critical infrastructure (GNWT, 2018). Climate change is also contributing to water scarcity, with some northern cities like Iqaluit preparing for water shortages by 2024. In addition to population growth and increasing demand, Iqaluit's water system is challenged by warmer weather and declining levels of rainfall that have led to water shortages (Bakaic et al., 2018).

Territorial governments have developed proactive plans to address water insecurity. For example, in 2014, Yukon released its water strategy and action plan with the overall goal of maintaining the quality, quantity, and 
health of Yukon water for both people and the environment. Priorities for achieving these goals include maintaining and improving access to safe drinking water, promoting the sustainable use of water, improving water management programs, and planning for water needs now and in the future (Government of Yukon, 2014). In Northwest Territories, the territorial government introduced its updated 2018 water plan, Northern Voices, Northern Waters: NWT Water Stewardship Strategy. The plan is a guide to long-term stewardship of water resources in the territory for maintaining the quality, quantity, and rates of flow of territorial waters, ensuring residents have access to safe, clean, and plentiful drinking water at all times, and ensuring that aquatic ecosystems remain healthy and diverse (GNWT, 2018). Notwithstanding these policy commitments, communities in northern Canada continue to be challenged by high rates of water insecurity, which leaves residents at heightened risk of experiencing a multitude of adverse health outcomes (Sarkar, Hanrahan, \& Hudson, 2015; Bressler and Hennessy, 2018).

\section{Energy (in) security}

Nearly all residents in northern Canada have access to electricity. However, the sources for energy vary, with much of the energy produced through non-renewable and inefficient technologies. Because of the long distances between populated areas in northern Canada, there is limited grid connectivity. Additionally, the northern territories generate a negligible amount of their own electricity, combining to produce less than $1 \%$ of the total electricity production in Canada (Government of Canada, 2019). While some areas have isolated power grids for electricity transmission, the remoteness of many communities in northern Canada makes it difficult, either due to high costs or the physical geography, to supply power through conventional distribution systems. Northern communities are therefore overly dependent on imported fuel, mainly diesel, to generate their power and electricity. Global shifts in energy prices are expected to further threaten the energy security of northern communities (Larsen \& Fondahl, 2015). There is, however, considerable regional variability in energy generation. For example, in Yukon, 95\% of the total electricity is derived from hydroelectric generation, although diesel and natural gas generation are required during periods when hydroelectric generation is insufficient to meet peak power demands. Yukon does have electricity transmission lines that connect the majority of the territory to its hydroelectric grid, although five communities remain offgrid and rely on diesel-fired generation exclusively.

In the Northwest Territories (NWT), roughly $75 \%$ of power is generated from hydroelectricity. The NWT has two regional hydro-based electricity grids, the Snare Grid north of Great Slave Lake and the Taltson Grid south of Great Slave Lake. In all, 26 of 33 NWT communities are able to receive electricity through transmission and distribution lines; however, remote 
communities and industries that are not connected to either grid rely primarily on diesel powered generators as their electricity source. Due to the low population density and relatively expensive generation costs, NWT residents pay among the highest electricity rates in the country, reaching approximately 30 cents per kilowatt hour (Government of Canada, 2019). The availability of hydroelectric power is also subject to annual and seasonal weather variabilities. For example, in 2017 which experienced limited precipitation, only $39 \%$ of the NWT's energy was derived from hydroelectric generation, with $57 \%$ generated from diesel, $2 \%$ from wind, $2 \%$ from natural gas, and $1 \%$ from solar power (Government of Canada, 2019). In response to energy insecurity, the Government of the NWT has introduced a draft 2030 Energy Strategy that calls for the installation of wind turbines and solar panels in smaller, off-grid communities to reduce their reliance on diesel power and to broaden connectivity to the existing hydroelectric power grids.

In Nunavut, nearly all of the territory's energy is produced from diesel-fueled power generation (Government of Canada, 2019). In the absence of electrical transmission grids, communities in Nunavut rely on standalone diesel generators for their energy needs. In total, approximately 55 million liters of diesel are consumed annually for power generation. Diesel fuel supplies are typically transported to communities during the summer and then stored for year-round use (Government of Canada, 2019). The Government of Nunavut has introduced solar technologies in some communities (for example, Iqaluit, Kugluktuk), and liquefied natural gas and biomass energies are being considered. Electrical transmission lines from Manitoba have also been proposed with construction potentially beginning as early as 2022 .

\section{Food (in) security}

In the 2014 State of Knowledge of Food Security in Northern Canada assessment, a stark picture was presented on the high rate of food insecurity experienced by Canada's northern communities, particularly among Indigenous populations. While northern food insecurity is experienced differently depending on one's age, gender, and the community and region in which one lives (Natcher et al., 2016), the overall statistics for northern Canada are nonetheless alarming. For example, it is estimated that Inuit living in Nunavut have the highest food insecurity rate of any Indigenous population in a developed country (CCA, 2014). Among Inuit children, 90\% experience conditions of hunger on a regular basis, $76 \%$ miss meals, and $60 \%$ often go an entire day without eating (Egeland, 2010). These conditions are contributing to delayed and declining physical, social, and emotional health among Indigenous youth (CCA, 2014). Households with children also report disproportionately high rates of food insecurity relative to households without children (CCA, 2014). For instance, the IPY Inuit Child Health Survey found that $70 \%$ of Inuit preschoolers in Nunavut lived in 
food insecure households, while $24 \%$ of children under five years old lived in homes reporting severe food insecurity (Egeland, 2009). Furthermore, according to the 2007-2008 Nunavut Inuit Child Health Survey, only one third of Inuit children had healthy body weights for their age or height and $72 \%$ of children had decayed or extracted teeth (Egeland, 2009). Altogether, the high rates of food insecurity experienced by northern communities have contributed to a general decline in the physical (Compher, 2006), nutritional (Kuhnlein, Receveur, Soueida, \& Egeland, 2004) and emotional health (CCA, 2014) of northern residents.

The challenges associated with security in the northern food systems have been further exacerbated by extraordinarily high commercial foods costs in northern communities. For example, the Action Canada Foundation (2014) estimated that the purchase price of food items in Nunavut were $140 \%$ higher on average than the purchase price for the same food products in southern Canada. In the community of Old Crow, Yukon, residents pay an average of $\$ 496 /$ week for a healthy food basket. This same food basket can be purchased for \$206 in the Yukon's capital city of Whitehorse (Natcher et al., 2016). These cost differences can be attributed to the added expense of northern transport (estimated $>20 \%$ ) (Sorobey, 2013), higher electricity rates (roughly 84\%) (CCA, 2014), and additional labor, storage, and building maintenance costs (Duhaime \& Caron, 2013). When combined, these added costs result in northern residents paying as much as $\$ 13$ for a head of cauliflower, $\$ 9$ per kilogram $(\mathrm{kg}$ ) for tomatoes, and $\$ 7 / \mathrm{kg}$ for carrots (Nunavut Food Price Survey, 2017).

To offset these costs, the federal government has, since 2011, provided subsidies to northern retailers who are then expected to pass those savings on to consumers. For example, in 2016 Nutrition North Canada (NNC) spent $\$ 64.8$ million to subsidise the northern transport of 25.5 million kg of perishable goods. This included $\$ 21$ million (32\% of budget) to subsidise the shipment of 7.4 million $\mathrm{kg}$ of fruits and vegetables. However, a review of NNC found that the volumes and delivery times for food shipments remained highly variable, resulting in compromised food quality and reduced consumer acceptability. Despite the best intentions of NNC, high costs, coupled with poor retail quality, often removes fruits and vegetables from household food baskets; foods that are then replaced by non-perishable foods that lack equivalent nutritional value. These conditions have added to what many characterise as a public health crisis in northern Canada (CCA, 2014).

\section{Data and methodology}

\section{Data}

When assessing SDG indicator data, the United Nations (2018) suggests that data should be disaggregated as much as possible, for example by sex, age, race or ethnicity, and geographic location. To assess SDG target interactions 
in northern Canada, we drew on various public data sources made available by federal and territorial governments and various published resources on Arctic well-being and development. For example, much of the primary energy data was from the Government of Canada's National Energy Board (2019), which provided energy profiles describing the energy production, energy consumption, electricity use, and greenhouse gas (GHG) emissions in each territory. We examined these energy profiles for each territory separately to assess energy security throughout the Canadian Arctic. We also considered the GHG emissions related to energy production in order to evaluate the climaterelated impacts of producing power in these regions. In addition to these data sources, territorial governments have developed their own strategic planning documents for WEF sectors. These include, for example, the Yukon's 5 Year Strategic Plan for Energy (2019-2024), the Yukon Water Strategy and Action Plan, and the Local Food Strategy for Yukon (2016-2021).

Additional indicator data were derived from various 'state of knowledge' reports, such as the Arctic Human Development Report (Larsen \& Fondahl, 2015), the Survey of Living Conditions in the Arctic (SLiCA) (Poppel, 2015), Aboriginal Food Security in Northern Canada (CCA, 2014), and the Inuit Adult and Children's Health Surveys (Egeland, 2009; Egeland, 2010). These data sources may not align perfectly with U.N. recommended data sources, but they do provide a relatively accurate proxy representation of the indicators for northern Canada.

\section{Methods}

Various approaches have been used for analyzing and measuring trade-offs and synergies between WEF systems (Endo et al., 2015). For this research we adopted the approach developed by Fader et al. (2018) who, building on Nilsson et al. (2016), provides a step-wise methodology for calculating and ranking the degree of interaction between WEF-SDG targets. Whereas Fader et al. (2018) conducted their analysis on an international scale, we adapted their methodology for regional application in northern Canada.

In this approach, positive interactions between WEF-SDG targets occur when common infrastructure requirements are required to achieve each target and when the targets have a positive net impact on ecosystem services. Conversely, negative interactions occur when two targets require the same scarce resource inputs and if the target pair imposes a negative net impact on ecosystem services. The magnitude of the synergy or trade-off between any two targets is then represented by the sum of the positive and negative interactions between the two targets, where positive sums indicate synergies and negative sums indicate trade-offs between two targets. This methodology has been widely employed due to its transparency and for illustrating the inherent connections between WEF targets.

This methodology does have limitations, most notably in the method's subjectivity. Because each interaction score depends on the expert knowledge, 
considerations, and information available to those conducting the analysis, some interpretation is required. Thorough and careful consideration needs to be given to how each target could be met, as it could alter the resulting interaction scores. For example, target 2.1, ending hunger, could be met through conventional food production and transportation methods or through traditional food procurement methods such as hunting and fishing, with each method requiring different input and infrastructure needs that require consideration. This subjectivity could lead researchers to reach different conclusions based on their considerations of how each SDG target could or would be met. Notwithstanding this limitation, this methodology does make apparent the various interactions that occur between WEF-SDG targets in an accessible and transparent format.

In our analysis, we first evaluated the resource input needs, infrastructure requirements, and the risks and benefits toward ecosystem services associated with achieving each target. Three resource inputs were assessed for each target: (1) water, (2) land and soil, and (3) electricity and fuel. A negative interaction occurs between two targets if they both require the same input since they are considered to be in competition for that scarce resource. Therefore, $a-1$ is attributed to the total interaction score for each input that both targets require.

Similarly, three types of infrastructure requirements were evaluated for each SDG target: (1) health care and hospitals, (2) education, technology, and research, and (3) "gray infrastructure", which includes infrastructure such as streets, pipes, rails, airports, dams, energy production, sewage, and water treatment. Contrary to input needs, a positive interaction occurs between two targets when they require the same infrastructure type since it is assumed that the required infrastructure can be used or developed in a way that helps achieve both targets. Therefore $\mathrm{a}+1$ is attributed to the total interaction score for each infrastructure type that both targets require.

Lastly, each SDG target was evaluated in terms of if the potential risks or benefits it posed toward provisioning and regulating ecosystem services. Supporting ecosystem services were included within regulating services for the purpose of this analysis. A value of -1 is assigned for each ecosystem service the target poses a risk to, +1 is assigned for each ecosystem service the target produces benefits toward, and 0 is assigned if the target has no impact on the ecosystem service. If the net benefits from the two groups of ecosystem services outweigh the risks, +1 is attributed to the total interaction score for that target pair. Conversely, -1 is attributed to the total interaction score if the net ecosystem service risks are greater than the benefits. If the risks and benefits to ecosystem services between two targets are equal, no score is attributed to the total interaction score.

Every pairwise combination of targets in SDGs 2, 6, and 7 were evaluated in this manner. The total interaction score (TIS) between two targets is the sum of the negative input interactions, positive infrastructure interactions, and the net effect on ecosystem services. Written in equation form, this 
Table 14.2 Scale of possible total interaction scores between WEF-SDG targets

\begin{tabular}{|l|l|l|}
\hline Interaction & Name & Explanation \\
\hline-4 & Cancelling & Makes it impossible to reach another goal. \\
\hline-3 & Restricting & Obstructs the achievement of another goal. \\
\hline-2 & Counteracting & Clashes with another goal. \\
\hline-1 & Constraining & Limits options on another goal. \\
\hline 0 & Consistent & No net positive or negative interactions. \\
\hline+1 & Enabling & Creates conditions that further another goal. \\
\hline+2 & Reinforcing & Aids the achievement of another goal. \\
\hline+3 & Supporting & Strongly facilitates the achievement of another goal. \\
\hline+4 & Indivisible & Inextricable linked to the achievement of another goal. \\
\hline
\end{tabular}

appears as TIS $=\mathrm{RI}+\mathrm{INF}+\mathrm{ES}$ where RI is the resource input trade-offs impact, INF is the infrastructure synergies impact, and ES is the ecosystem services impact. RI can range in value from -3 to 0 , INF can range in value from 0 to +3 , and $E S$ can take on a value of -1 if ecosystem services risks are greater than benefits, +1 if ecosystem services benefits are greater than risks, and 0 if the benefits and risks are equal or there are no risks or benefits. Therefore, the total interaction score for any pair of targets can range from -4 to +4 , where the greater the absolute value of the total interaction score, the greater the magnitude or strength of the trade off or synergy is between the two targets (Table 14.2).

\section{Results}

\section{SDG target interactions}

Out of 210 interactions, only 12 were found to be negative, while 15 target pairs had no interacting effect (Table 14.3). Only three interaction scores were lower than -1 , whereas 132 are greater than +1 . Overall, roughly $87 \%$ of all interactions were found to be synergistic of some magnitude. This indicates that achieving or addressing one WEF target would have positive spillover effects on the others. Our findings are consistent with other WEF assessments, which have typically found that synergies between targets outweigh the trade-offs (Fuso Nerini et al., 2018; McCollum et al., 2018). For example, Fader et al.'s (2018) global WEF assessment determined 166 synergistic interactions to only 26 trade-offs, with water-related targets having the most synergistic potential.

One reason for the large number of synergies is the positive impacts on ecosystem services. By design, the SDG targets almost universally promote ecosystem services, and one point is added to the total interaction score of any two targets that result in a net positive environmental impact. This is especially important in northern Canada where WEF targets that benefit ecosystem services can assist in climate change mitigation. The need for 
Table 14.3 Interaction scores between WEF-SDGs 2,6, 7 targets for Northern Canada

\begin{tabular}{|l|lllllllllllllllllllll|}
\hline \multicolumn{1}{|c}{} & 2.1 & 2.2 & 2.3 & 2.4 & 2.5 & $2 . \mathrm{a}$ & $2 . \mathrm{b}$ & $2 . \mathrm{c}$ & 6.1 & 6.2 & 6.3 & 6.4 & 6.5 & 6.6 & $6 . \mathrm{a}$ & $6 . \mathrm{b}$ & 7.1 & 7.2 & 7.3 & $7 . \mathrm{a}$ & $7 . \mathrm{b}$ \\
\hline & & -2 & -2 & 0 & 2 & 2 & -1 & -1 & 1 & 0 & 2 & 2 & 2 & 0 & 2 & 2 & -1 & 1 & 1 & 2 & 1 \\
2.2 & -2 & & -2 & 0 & 2 & 2 & -1 & -1 & 1 & 0 & 2 & 2 & 2 & 0 & 2 & 2 & -1 & 1 & 1 & 2 & 1 \\
2.3 & -2 & -2 & & 0 & 2 & 2 & -1 & -1 & 1 & 0 & 2 & 2 & 2 & 0 & 2 & 2 & -1 & 1 & 1 & 2 & 1 \\
2.4 & 0 & 0 & 0 & & 2 & 3 & 1 & 1 & 1 & 1 & 2 & 2 & 2 & 0 & 2 & 2 & 1 & 2 & 3 & 3 & 2 \\
2.5 & 2 & 2 & 2 & 2 & & 2 & 1 & 1 & 2 & 2 & 2 & 2 & 2 & 2 & 2 & 2 & 2 & 2 & 2 & 2 & 2 \\
$2 . \mathrm{a}$ & 2 & 2 & 2 & 3 & 2 & & 1 & 1 & 3 & 3 & 3 & 3 & 2 & 2 & 2 & 2 & 3 & 3 & 3 & 3 & 3 \\
$2 . \mathrm{b}$ & -1 & -1 & -1 & 1 & 1 & 1 & & 0 & 1 & 1 & 1 & 1 & 1 & 1 & 1 & 1 & 0 & 1 & 0 & 1 & 1 \\
$2 . \mathrm{c}$ & -1 & -1 & -1 & 1 & 1 & 1 & 0 & & 1 & 1 & 1 & 1 & 1 & 1 & 1 & 1 & 0 & 1 & 0 & 1 & 1 \\
6.1 & 1 & 1 & 1 & 1 & 2 & 3 & 1 & 1 & & 1 & 2 & 2 & 2 & 1 & 2 & 2 & 1 & 2 & 3 & 3 & 2 \\
6.2 & 0 & 0 & 0 & 1 & 2 & 3 & 1 & 1 & 1 & & 2 & 2 & 2 & 1 & 2 & 2 & 1 & 2 & 3 & 3 & 2 \\
6.3 & 2 & 2 & 2 & 2 & 2 & 3 & 1 & 1 & 2 & 2 & & 3 & 2 & 2 & 2 & 2 & 2 & 3 & 3 & 3 & 2 \\
6.4 & 2 & 2 & 2 & 2 & 2 & 3 & 1 & 1 & 2 & 2 & 3 & & 2 & 1 & 2 & 2 & 2 & 2 & 3 & 3 & 3 \\
6.5 & 2 & 2 & 2 & 2 & 2 & 2 & 1 & 1 & 2 & 2 & 2 & 2 & & 2 & 2 & 2 & 2 & 2 & 2 & 2 & 2 \\
6.6 & 0 & 0 & 0 & 0 & 2 & 2 & 1 & 1 & 1 & 1 & 2 & 1 & 2 & & 2 & 2 & 1 & 1 & 2 & 2 & 2 \\
$6 . \mathrm{a}$ & 2 & 2 & 2 & 2 & 2 & 2 & 1 & 1 & 2 & 2 & 2 & 2 & 2 & 2 & & 2 & 2 & 2 & 2 & 2 & 2 \\
$6 . \mathrm{b}$ & 2 & 2 & 2 & 2 & 2 & 2 & 1 & 1 & 2 & 2 & 2 & 2 & 2 & 2 & 2 & & 2 & 2 & 2 & 2 & 2 \\
7.1 & -1 & -1 & -1 & 1 & 2 & 3 & 0 & 0 & 1 & 1 & 2 & 2 & 2 & 1 & 2 & 2 & & 2 & 2 & 3 & 2 \\
7.2 & 1 & 1 & 1 & 2 & 2 & 3 & 1 & 1 & 2 & 2 & 3 & 2 & 2 & 1 & 2 & 2 & 2 & & 3 & 3 & 3 \\
7.3 & 1 & 1 & 1 & 3 & 2 & 3 & 0 & 0 & 3 & 3 & 3 & 3 & 2 & 2 & 2 & 2 & 2 & 3 & & 3 & 3 \\
$7 . \mathrm{a}$ & 2 & 2 & 2 & 3 & 2 & 3 & 1 & 1 & 3 & 3 & 3 & 3 & 2 & 2 & 2 & 2 & 3 & 3 & 3 & & 3 \\
$7 . \mathrm{b}$ & 1 & 1 & 1 & 2 & 2 & 3 & 1 & 1 & 2 & 2 & 2 & 3 & 2 & 2 & 2 & 2 & 2 & 3 & 3 & 3 & \\
\hline 0
\end{tabular}

research, technology, education, and improved infrastructure in northern Canada also contributes to the present synergies. For example, building roads, water lines, or clean power sources in or between communities can improve access to food, water, and clean energy that could help achieve multiple targets simultaneously.

All negative interactions involve at least one target from SDG 2 (zero hunger). This is primarily due to the significant amount of resources needed to achieve targets in SDG 2 such as ending hunger (2.1), ending malnutrition (2.2), and increasing agricultural productivity (2.3). These targets all require intensive resource inputs such as land, water, energy, and fuel in order to be met, and since there is a limited amount of these inputs available, trade-offs occur between the targets that need and consume these scarce resources. For example, in order to eliminate hunger, a strategy may be to increase agricultural production. However, increased agricultural output may require a greater use of inputs (for example, synthetic fertiliser), which necessitates increased energy consumption and may pose adverse effects on water quality and quantity, both resulting in trade-offs.

To illustrate the target pair assessment procedure in practice, consider the interaction between the target pair of 2.2, to end malnutrition, and 2.3, to double agriculture productivity and incomes of small-scale food producers, as an example. Ending malnutrition in northern Canada will require all three input groups as water, land and soil, and electricity and fuel will be required whether the food is produced in northern Canada or elsewhere 
and then transported to the region. Similarly, all three input groups are required to double agriculture productivity and income as they are all necessary for food production by conventional agriculture or by harvesting wildlife from natural habitats and fisheries. Therefore, the two targets are in competition for all three resources, resulting in a -3 contribution to the total interaction score.

In terms of infrastructure needs, all three infrastructure groups are also deemed necessary to end malnutrition. Health care would be needed to assess the prevalence of malnutrition among northern residents and possibly provide nutritional supplements to address and mitigate malnutrition. Technology and research would be required to increase food production while streets, rails, airports, or other types of gray infrastructure would be required to transport food and health care to northern regions with limited access. Increasing food production and distribution would also require education, technology, and research as well as gray infrastructure to produce, transport, and sell commercial food products. However, target 2.3 does not require health care or hospital infrastructure to be achieved. Therefore, there are two infrastructure synergies between targets 2.2 and 2.3, resulting in $\mathrm{a}+2$ contribution to the total interaction score.

We then examine and assess the impact each target could have on ecosystem services. Ending malnutrition could pose benefits and risks to provisioning services as there would be benefits from greater food production, but achieving this could also reduce the availability of other resources or raw materials such as water and forested land. Achieving target 2.3 could pose similar risks and benefits to provisioning services as ending malnutrition. Therefore, the presence of both risks and benefits for each target results in a zero-sum impact. For regulating services, both targets could pose risks as the actions necessary to achieve each target could negatively impact climate regulation, water quality, or wildlife habitats for example. While efforts could be made to minimise the negative impacts on regulating services, any action taken to achieve either target was deemed unlikely to provide benefits toward regulating services. Therefore, the risks toward regulating services outweighed the benefits for the two targets, resulting in a -1 score.

We then calculate the total interaction score for targets 2.2 and 2.3 as the sum of the results from the input trade-offs, infrastructure synergies, and net ecosystem services impact. Both targets required all three inputs, resulting in a -3 score, while the targets shared two infrastructure requirements resulting in $\mathrm{a}+2$ score, and the net ecosystem service impact was deemed to be negative resulting in a score of -1 . Therefore, the total interaction score for targets 2.2 and 2.3 was -2 , indicating that the targets are counteracting and are in competition with one another (Table 14.4).

For comparison, we can also consider a case where a positive interaction score occurs using the target pair of 6.3, to improve water quality through a variety of methods, and 7.2, to substantially increase the share of renewable 
Table 14.4 Example of a negative interaction score

\begin{tabular}{|c|c|c|c|c|c|c|c|c|c|c|c|}
\hline \multirow[t]{2}{*}{ Target } & \multicolumn{3}{|c|}{$\begin{array}{c}\text { Inputs: }-1 \text { if competing; } \\
0 \text { if no interaction; }+1 \text { if } \\
\text { complimentary }\end{array}$} & \multicolumn{3}{|c|}{$\begin{array}{l}\text { Infrastructure: }-1 \text { if competing; } 0 \text { if } \\
\text { no interaction; }+1 \text { if complimentary }\end{array}$} & \multicolumn{2}{|c|}{$\begin{array}{l}\text { Provisioning Ecosystem } \\
\text { Services }\end{array}$} & \multicolumn{2}{|c|}{$\begin{array}{c}\text { Regulating } \\
\text { Ecosystem } \\
\text { Services }\end{array}$} & \\
\hline & Water & Land $\backslash$ Soil & Elec.\Fuel & $\begin{array}{l}\text { Health. \& } \\
\text { Hospitals }\end{array}$ & $\begin{array}{c}\text { Ed. \& } \\
\text { Research }\end{array}$ & $\begin{array}{c}\text { Gray } \\
\text { Infrastructure }\end{array}$ & Risk & Benefit & Risk & Benefit & \\
\hline 2.2 & -1 & -1 & -1 & 1 & 1 & 1 & -1 & 1 & -1 & 0 & \\
\hline 2.3 & -1 & -1 & -1 & 0 & 1 & 1 & -1 & 1 & -1 & 0 & \\
\hline Interaction & -1 & -1 & -1 & 0 & 1 & 1 & \multicolumn{2}{|c|}{0} & \multicolumn{2}{|c|}{-1} & \\
\hline Total & \multicolumn{3}{|c|}{-3} & \multicolumn{3}{|c|}{2} & \multicolumn{4}{|c|}{-1} & $\begin{array}{c}\text { TIS - } \\
2\end{array}$ \\
\hline
\end{tabular}

energy. The resource inputs deemed necessary for target 6.3 were electricity and fuel, which could be used to reduce the amount of untreated wastewater, a component of the target, in order to improve water quality. Target 7.2 could require water as a renewable energy source, while the other input groups were deemed unnecessary as any land, soil, electricity, or fuel requirements would be negligible. Therefore, the two targets do not share any input needs and no negative score is attributed to the total interaction. In terms of infrastructure, health care and hospitals would not be required for either target. Education, research, and technology could help reduce pollutants, treat wastewater, and increase recycling to improve water quality while also helping develop and establish renewable energy sources. Similarly, gray infrastructure such as pipes, sewage, and water treatment facilities could improve water quality while energy production infrastructure could aid the development of renewable energy sources. Therefore $a+2$ is attributed to the total interaction score for these two shared infrastructure needs. Lastly, neither target poses risks toward any ecosystem service group but they do provide benefits. Improving water quality would benefit both provisioning and regulating services, while implementing renewable energy sources would reduce pollution produced from non-renewable energy sources in the region and therefore benefit regulating services. Therefore, achieving targets 6.3 and 7.2 would have a net positive effect on ecosystem services, resulting in a +1 score attributed to the total interaction score. The sum of the interaction scores is then +3 between targets 6.3 and 7.2, indicating that these targets are supporting and each target strongly facilitate the achievement of the other (Table 14.5).

Table 14.5 Example of a positive interaction score

\begin{tabular}{|c|c|c|c|c|c|c|c|c|c|c|c|}
\hline \multirow[t]{2}{*}{ Target } & \multicolumn{3}{|c|}{$\begin{array}{c}\text { Inputs: }-1 \text { if competing; } \\
0 \text { if no interaction; }+1 \text { if } \\
\text { complimentary }\end{array}$} & \multicolumn{3}{|c|}{$\begin{array}{l}\text { Infrastructure: }-1 \text { if competing; } 0 \text { if } \\
\text { no interaction; }+1 \text { if complimentary }\end{array}$} & \multicolumn{2}{|c|}{$\begin{array}{c}\text { Provisioning } \\
\text { Ecosystem Services }\end{array}$} & \multicolumn{2}{|c|}{$\begin{array}{c}\text { Regulating } \\
\text { Ecosystem } \\
\text { Services } \\
\end{array}$} & \\
\hline & Water & Land $\backslash$ Soil & Elec. $\backslash$ Fuel & $\begin{array}{l}\text { Health. \& } \\
\text { Hospitals }\end{array}$ & $\begin{array}{c}\text { Ed. \& } \\
\text { Research }\end{array}$ & $\begin{array}{c}\text { Gray } \\
\text { Infrastructure }\end{array}$ & Risk & Benefit & Risk & Benefit & \\
\hline 6.3 & 0 & 0 & -1 & 0 & 1 & 1 & 0 & 1 & 0 & 1 & \\
\hline 7.2 & -1 & 0 & 0 & 0 & 1 & 1 & 0 & 0 & 0 & 1 & \\
\hline Interaction & 0 & 0 & 0 & 0 & 1 & 1 & & & & 1 & \\
\hline Total & & 0 & & & 2 & & & 1 & & & $\begin{array}{l}\text { TIS } \\
3\end{array}$ \\
\hline
\end{tabular}




\section{Conclusion}

This research was conducted as a pilot to demonstrate the potential usefulness of WEF nexus research in Arctic regions. Although WEF nexus research has been conducted in countries and regions throughout the world, no such studies have been conducted in the Arctic. A focus on northern Canada was particularly warranted given the high rates of WEF insecurity that are being experienced by northern communities, particularly among the Indigenous population. These insecurities are reflected in limited access to clean water, an over-dependence on non-renewable energy sources, and having the highest rates of Indigenous food insecurity among all industrialised nations. As unacceptable as these current conditions are, these insecurities will likely be compounded by the effects of climate change.

Owing to the high rates of WEF insecurity in northern Canada, our methodology was motivated by the need for integrative thinking that makes visible the interconnectedness of WEF systems. Historically, WEF systems have been treated independently with little policy or institutional coordination occurring between sectors (Nilsson, Griggs, \& Visbeck, 2016; Rasul, 2016). The goal of this research was to highlight their inherent connections in order to support decision-makers in identifying sustainable solutions to WEF related challenges. In doing so, we found that the synergies between WEF-SDGs far outweigh the potential trade-offs. In total, $87 \%$ of all interactions were found to be synergistic of some magnitude. This indicates that achieving or addressing one WEF target would have positive spillover effects for the others.

This assessment ultimately illustrates that interactions and connections exist between almost all WEF targets. Policy and decision makers should consider how each target interacts with others when addressing WEF security in order to take advantage of positive interactions and minimise negative outcomes. Having synergies significantly outweigh trade-offs signals an opportunity to simultaneously address multiple WEF-SDG targets in northern Canada through mutually beneficial actions that capitalise on and promote synergetic policies. This information can now be used to inform integrated planning efforts that are cognizant of respective resource requirements for achieving WEF security in northern Canada.

As informative as our findings may be, we encourage future WEF analyses to be conducted at regional and sub-regional scales. Regional differences exist in population, geography, economy, and access to new technologies. Conducted at finer scales, WEF nexus assessments could promote more nimble policy responses than are not so easily achieved at the national level. Regional WEF assessments may also prove more effective at incorporating the social and cultural values of residents as assessment criteria. Where cultural values are known, the methodology can be expanded to include an evaluation of the potential impacts on cultural ecosystem services, Indigenous livelihoods, and the territorial rights and interests of Indigenous 
peoples. Such considerations are consistent with the Arctic Council's framework for sustainable development, which calls for social equity, protecting and promoting cultures, and strengthening the capacity of Indigenous peoples (SDWG, 2017). The inclusion of Indigenous participation is also reflected in the Canadian government's commitment to respecting the rights of Indigenous peoples in Canada's national SDG strategy (BCCIC, 2019). Until those regional assessments are conducted, we are hopeful that this research can offer a pathway for untangling the inherent complexities of WEF systems in northern Canada.

\section{References}

Action Canada Foundation. (2014). Hunger in Nunavut: local food for healthier communities. Action Canada. http://www.actioncanada.ca/wp-content/ uploads/2014/04/TF-3-Hunger-in-Nunavut-EN.pdf.

Bakaic, M., Medeiros, A. S., Peters, J. F., \& Wolfe, B. B. (2018). Hydrologic monitoring tools for freshwater municipal planning in the Arctic: the case of Iqaluit, Nunavut, Canada. Environmental Science and Pollution Research, 25, 32913-32925. doi: https://doi.org/10.1007/s11356-017-9343-4

Bhaduri, A., Ringler, C., Dombrowski, I., Mohtar, R., \& Scheumann, W. (2015). Sustainability in the water-energy-food nexus. Water International: Sustainability in the water-energy-food nexus, 40(5-6), 723-732.

Biggs, E. M., Bruce, E., Boruff, B., Duncan, J. M., Horsley, J., Pauli, N., \& Mcneill, K. et al. (2015). Sustainable development and the water-energy-food nexus: A perspective on livelihoods. Environmental Science and Policy, 54, 389-397.

Bressler, J. M., \& Hennessy, T. W. (2018). Results of an Arctic Council survey on water and sanitation services in the Arctic. International Journal of Circumpolar Health, 77(1). doi: https://doi.org10.1080/22423982.2017.1421368.

British Columbia Council for International Cooperation (BCCIC). (2019). Sustainable development goals: developing national SDG implementation strategies. BCCIC. Available at: https://www.bccic.ca/bccic-policy-briefdeveloping-national-sdg-implementation-strategies/.

Compher, C. (2006). The nutrition transition in American Indians. Journal of Transcultural Nursing, 17(3), 217-223.

Costanza, R., Alperovitz, G., Daly, H. E., Farley, J., Franco, C., Jackson, T. ... Victor, P. (2015). Ecological economics and sustainable development: Building a sustainable and desirable economy-in-society-in-nature. Routledge International Handbook of Sustainable Development, 281-294.

Council of Canadian Academies. (2014). Aboriginal Food Security in Northern Canada: An Assessment of the State of Knowledge, Ottawa, ON. The Expert Panel on the State of Knowledge of Food Security in Northern Canada, Council of Canadian Academies. https://cca-reports.ca/wp-content/uploads/2018/10/foodsecurity_fullreporten.pdf

De Schutter, O. (2012). Report of the special rapporteur on the right to food (pp. 1-21). United Nations General Assembly.

Duhaime, G., \& Caron, A. (2013). Consumer price monitoring in Nunavik, 2011-2013. Canada Research Chair on Comparative Aboriginal People, University of Laval. https://www.nunivaat.org/doc/publication/Suivi-des-prix-2011-2013-ang.pdf 
Egeland, G. (with Qanuippitali Steering Committee Members). (2009). The International Polar Year Nunavut Inuit Child Health Survey 2007-2008. Centre for Indigenous Peoples' Nutrition and Environment (CINE), McGill University. https://www.mcgill.ca/cine/files/cine/child_inuit_health_survey_aug_31.pdf.

Egeland, G. (With Nunavut Steering Committee, CINE staff members, and graduate students). (2010). Inuit Health Survey 2007-2008: Nunavut. Centre for Indigenous Peoples' Nutrition and Environment (CINE), Mc Gill University. https:// www.mcgill.ca/cine/files/cine/adult_report_nunavut.pdf.

Endo, A., Burnett, K., Orencio, P. M., Kumazawa, T., Wada, C. A., Ishii, A. ... Taniguchi, M. (2015). Methods of the water-energy-food nexus. Water, 7(10), 5806-5830. https://doi.org/10.3390/w7105806

Endo, A., Tsurita, I., Burnett, K., \& Orencio, P. M. (2017). A review of the current state of research on the water, energy, and food nexus. Journal of Hydrology, 11, 20-30. https://doi.org/10.1016/j.ejrh.2015.11.010

Environmentand ClimateChangeCanada.(2013). Water-how weuseit. Government of Canada. http://www.ec.gc.ca/eau-water/default.asp?lang=en\&n=0bbd794b-1\#a8.

Fader, M., Cranmer, C., Lawford, R., \& Engel-Cox, J. (2018). Toward an understanding of synergies and trade-offs between water, energy, and food SDG targets. Frontiers in Environmental Science, 6.

Fuso Nerini, F., Tomei, J., To, L. S., Bisaga, I., Parikh, P., Black, M., \& Borrion, A. et al. (2018). Mapping synergies and trade-offs between energy and the sustainable development goals. Nature Energy, 3(1), 10-15. 10.1038/s41560-017-0036-5.

Government of Canada: National Energy Board. (2019). Provincial and Territorial Energy Profiles. Government of Canada. https://www.neb-one.gc.ca/nrg/ntgrtd/ $\mathrm{mrkt} / \mathrm{nrgsstmprfls} /$ index-eng.html.

Government of Yukon. (2014). Water for nature, water for people: Yukon water strategy and action plan. Government of Yukon. http://www.env.gov.yk.ca/ publications-maps/documents/Yukon_Water_Strategy_Action_Plan.pdf.

Kuhnlein, H. V., Receveur, O., Soueida, R., \& Egeland, G. M. (2004). Arctic indigenous peoples experience the nutrition transition with changing dietary patterns and obesity. The Journal of Nutrition, 134(6), 1447-1453.

Kulat, M. I., Mohtar, R. H., \& Olivera, F. (2019). Holistic water-energy-food nexus for guiding water resources planning: Matagorda county, Texas case. Frontiers in Environmental Science, 7, 3.

Larsen, J. N., \& Fondahl, G. (Eds.). (2015). Arctic Human Development Report: Regional Processes and Global Linkages. Nordisk Ministerråd. http://norden. diva-portal.org/smash/get/diva2:788965/FULLTEXT03.pdf.

Lim, M. M. L., Søgaard Jørgensen, P., \& Wyborn, C. A. (2018). Reframing the sustainable development goals to achieve sustainable development in the anthropocene-a systems approach. Ecology and Society, 23(3), 22. doi: https://doi. org/10.5751/ES-10182-230322.

Liu, Q. (2016). Interlinking climate change with water-energy-food nexus and related ecosystem processes in California case studies. Ecological Processes, 5(1), 1-14.

Mainali, B., Luukkanen, J., Silveira, S., \& Kaivo-Oja, J. (2018). Evaluating synergies and trade-offs among sustainable development goals (SDGs): Explorative analyses of development paths in. South Asia and Sub-Saharan Africa. Sustainability, $10(3), 815$. 
McCollum, D. L., Gomez Echeverri, L., Busch, S., Pachauri, S., Parkinson, S., Rogelj, J. ... Stevance, A. S. (2018). Connecting the sustainable development goals by their energy inter-linkages. Environmental Research Letters, 13(3), 033006.

Natcher, D., Shirley, S., Rodon, T., \& Southcott, C. (2016). Constraints to wildlife harvesting among aboriginal communities in Alaska and Northern Canada. Food Security, 8(6), 1153-1167.

Nilsson, M., Griggs, D., \& Visbeck, M. (2016). Map the interactions between sustainable development goals. Nature, 534(7607), 320-322.

Nilsson, M., \& Costanza, R. (2015). Overall framework for the sustainable development goals. Review of Targets for the Sustainable Development Goals: the Science Perspective, 7-12.

Nunavut Food Price Survey. (2017). Price comparisons per kilogram and litre. Government of Nunavut. https://www.gov.nu.ca/sites/default/files/2017_nunavut_ food_price_survey_-_price_comparisons_per_kilogram_and_litre_report_1. pdf.

Pirkle, C., Lucas, M., Dallaire, R., Ayotte, P., Jacobson, J., Jacobson, S. ... Muckle, G. (2014). Food insecurity and nutritional biomarkers in relation to stature in Inuit children from Nunavik. Canadian Journal of Public Health, 105(4), e233-e238. doi: https://doi.org/10.17269/cjph.105.4520.

Pittock, J., Orr, S., Stevens, L., Aheeyar, M., \& Smith, M. (2015). Tackling trade-offs in the nexus of water, energy and food. Aquatic Procedia, 5, 58-68.

Poppel, B. (Eds.). (2015). SLiCA: Arctic living conditions: living conditions and quality of life among Inuit, Saami, and indigenous peoples of Chukota and the Kola Peninsula. Nordisk Ministerråd. http://norden.diva-portal.org/smash/get/diva2:790312/ FULLTEXT02.pdf.

Pradhan, P., Costa, L., Rybski, D., Lucht, W., \& Kropp, J. P. (2017). A systematic study of sustainable development goal (SDG) interactions. Earth's Future, 5(11), $1169-1179$.

Rasul, G. (2016). Managing the food, water, and energy nexus for achieving the sustainable development goals in South Asia. Environmental Development, 18, 14-25.

Sarkar, A., Hanrahan, M., \& Hudson, A. (2015). Water insecurity in Canadian Indigenous communities: Some inconvenient truths. Rural and Remote Health, 15, 3354. www.rrh.org.au/journal/article/3354

Sorobey, M. (2013). Northwest Company [Paper Presentation]. Northern Exposure 2 Conference: Realities of Remote Logistics, Winnipeg, Manitoba, Canada.

Sustainable Development Working Group (SDWG). (2017). Strategic Framework 2017. $S D W G$. https://www.sdwg.org/wp-content/uploads/2017/04/SDWG-Framework2017-Final-Print-version.pdf.

United Nations. (2018). Global indicator framework for the Sustainable Development Goals and targets of the 2030 Agenda for Sustainable Development. UN Statistics. https://unstats.un.org/sdgs/indicators/Global\%20Indicator $\% 20$ Framework $\% 20$ after\%20refinement_Eng.pdf 